\title{
Rotaxanes and catenanes as prototypes of molecular machines and motors*
}

\author{
Christiane Dietrich-Buchecker, Maria Consuelo Jimenez-Molero, \\ Valerie Sartor, and Jean-Pierre Sauvage ${ }^{\ddagger}$
}

\begin{abstract}
Laboratoire de Chimie Organo-Minerale, UMR 7513 CNRS, Faculté de Chimie, Université Louis Pasteur, 4 rue Blaise Pascal, 67070 Strasbourg Cedex, France
\end{abstract}

\begin{abstract}
In the course of the last 20 years, our view on rotaxanes and catenanes has completely changed. Copper(I)-templated strategies, in particular, have allowed us to prepare catenanes on a real preparative scale, in a few chemical steps from commercially available compounds. A particularly significant improvement was the introduction of the recently developed ring-closing metathesis reaction, using Grubbs catalyst. The dynamic properties of rotaxanes and catenanes has been exploited to construct molecular systems for which one component can be set in motion under the action of an external signal, while the other components can be considered as motionless (artificial molecular "machines" and "motors"). A particularly representative example is that of a rotaxane dimer, whose overall length can be controlled chemically: A metal exchange reaction $\left(\mathrm{Cu}^{\mathrm{I}} / \mathrm{Zn}^{\mathrm{II}}\right)$ triggers a reversible contraction/stretching process of the same molecular assembly, in a way reminiscent of the functioning of biological muscles.
\end{abstract}

\section{INTRODUCTION}

Catenanes, rotaxanes, and knots are topologically nontrivial molecular objects, which have experienced a complete revival in the course of the last 20 years (Fig. 1). This revival is due to the marked interest of synthetic chemists for novel chemical species, but also to the fast development of so-called "nanosciences" and, within this context, to the burgeoning and rapidly expanding field of research referred to as "molecular machines and motors" [1].

A few decades ago, Schill and coworkers could make catenanes using very elegant but long synthetic routes [2]. In parallel with the important work done by the German group, Wasserman had detected catenanes, following a statistical strategy that obviously did not afford more than minute amounts [3]. If the making of relatively simple catenanes and rotaxanes used to be a real synthetic challenge only 20 years ago [2-4], this is no more true today. At the beginning of the 1980s, the situation changed dramatically when transition metals were proposed as templates to construct interlocking rings in an efficient way, following very short strategies $[5,6]$. This was the start of a second life for these compounds. Purely organic catenanes and rotaxanes were made, thanks to the introduction of elegant routes based on new templating principles (organic acceptor-donor interactions and hydrogen bonding) [7-9].

The present review article will discuss two particular aspects of synthetic catenanes and rotaxanes. In the first section, we will mention the early work done in our group, which led to the first $\mathrm{Cu}(\mathrm{I})$-complexed [2]catenane in a preparative fashion and the corresponding ligand ("catenand"). The

\footnotetext{
*Plenary lecture presented at the IUPAC Polymer Conference on the Mission and Challenges of Polymer Science and Technology (IUPAC PC2002), Kyoto, Japan, 2-5 December 2002. Other presentations are published in this issue, pp. 1359-1402.

${ }^{\ddagger}$ Corresponding author
} 

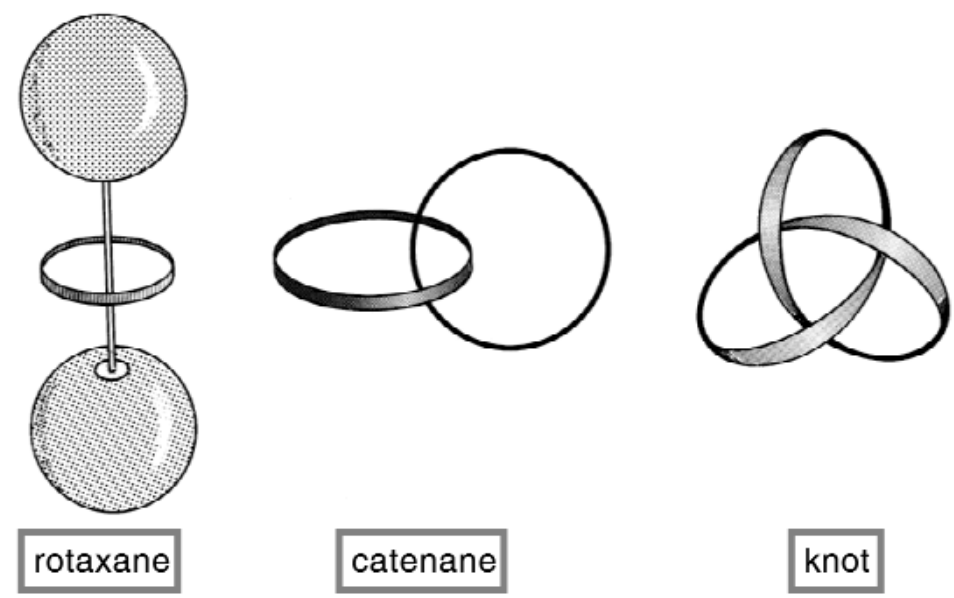

catenane

knot

Fig. 1 Cartoons of the simplest rotaxane, catenane, and knot.

$\mathrm{X}$-ray structures of the two prototypical compounds (complex and free catenane) will illustrate this section. In the second part, we will discuss the use of transition metal-based catenanes and rotaxanes as primitive molecular machines, with a particular emphasis on a rotaxane dimer whose overall length can be controlled at will by sending a chemical signal to the molecule. This latter system is thus reminiscent of muscles and can be proposed as a very simple model of natural muscles.

\section{Cu(I)-TEMPLATED SYNTHESIS OF CATENANES}

A Cu-coordinated catenane was successfully prepared by applying a 3D template synthesis around a transition metal. Subsequently, the corresponding metal-free assembly consisting of two non- or only weakly interacting interlocking rings was obtained.

To obtain interlocked rings, two strategies (Fig. 2) are possible: Both of them require that the ligand set around the metal center be adequate molecular threads that can be converted into rings in later stages. In addition, a key feature of the strategy is that the intermediate complex, precursor of the final metal-complexed catenane, contains two coordinating molecular threads disposed orthogonal to one another so as to afford an interlocking ring system after cyclization. The straightforward strategy A in-

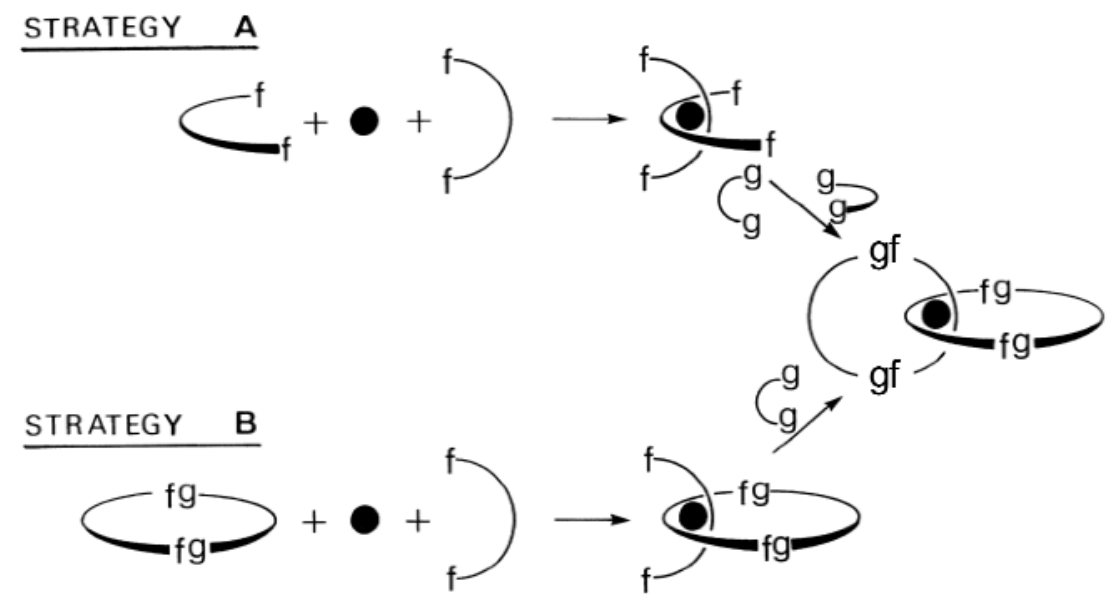

Fig. 2 Synthetic strategies leading to template synthesis of a [2]catenane. 
volves simultaneous pairwise connection between eight reacting centers. Strategy B implies the preliminary synthesis of a chelating macrocycle, but the final cyclization step involves only connection of four reacting centers. Although strategy B is longer than strategy A, it offers the advantage of a stepby-step procedure, and this less-risky route was tried first [5]. It is noteworthy that the first step of route $\mathrm{B}$ (i.e., threading of a macrocycle by a linear molecule) is common to the synthetic ways leading to catenanes consisting of two or several different rings [10,11] or to rotaxanes [12].

The one-step procedure afforded the desired interlocking ring-ensemble in a particularly straightforward strategy (Figs. 3 and 4). In the synthesis of $\mathbf{C u}(\mathbf{1})^{+}$described here, and for most of the catenanes synthesized later in our group, the coordinating core is based on 2,9-diphenyl-1,10-phenanthroline (dpp). Combining $\mathrm{Cu}(\mathrm{I})$ ions and dpp fragments proved to be an ideal association for a templated synthesis of catenanes. Indeed, in the presence of $\mathrm{Cu}(\mathrm{I})$, dpp forms a pseudotetrahedral complex of high stability [13] in which two dpp units fit in around the metal center [14]. The only additional requirement to use $\mathrm{Cu}(\mathrm{I})$ complexes with such topography as building blocks was the possibility to functionalize the ligands beyond the coordination sites. 2,9-bis( $p$-anisyl)-1,10-phenanthroline is easily con-

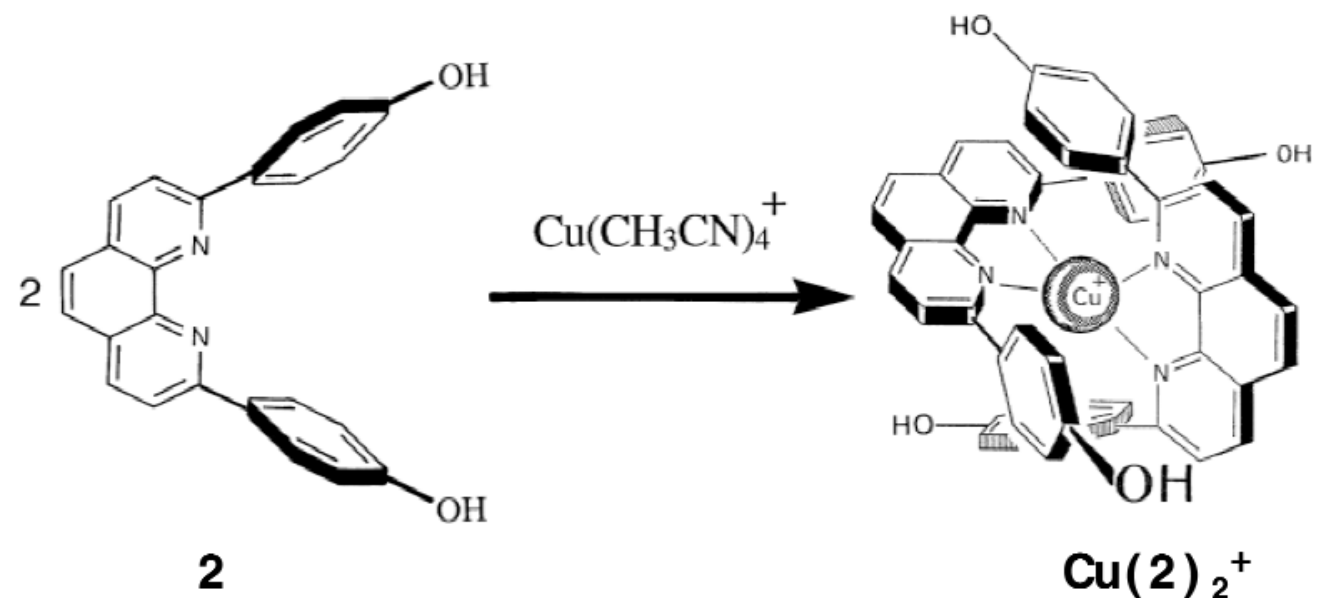

Fig. 3 Template synthesis of the pre-catenane $\mathbf{C u}(2)_{2}{ }^{+}$.

$(100 \%)$

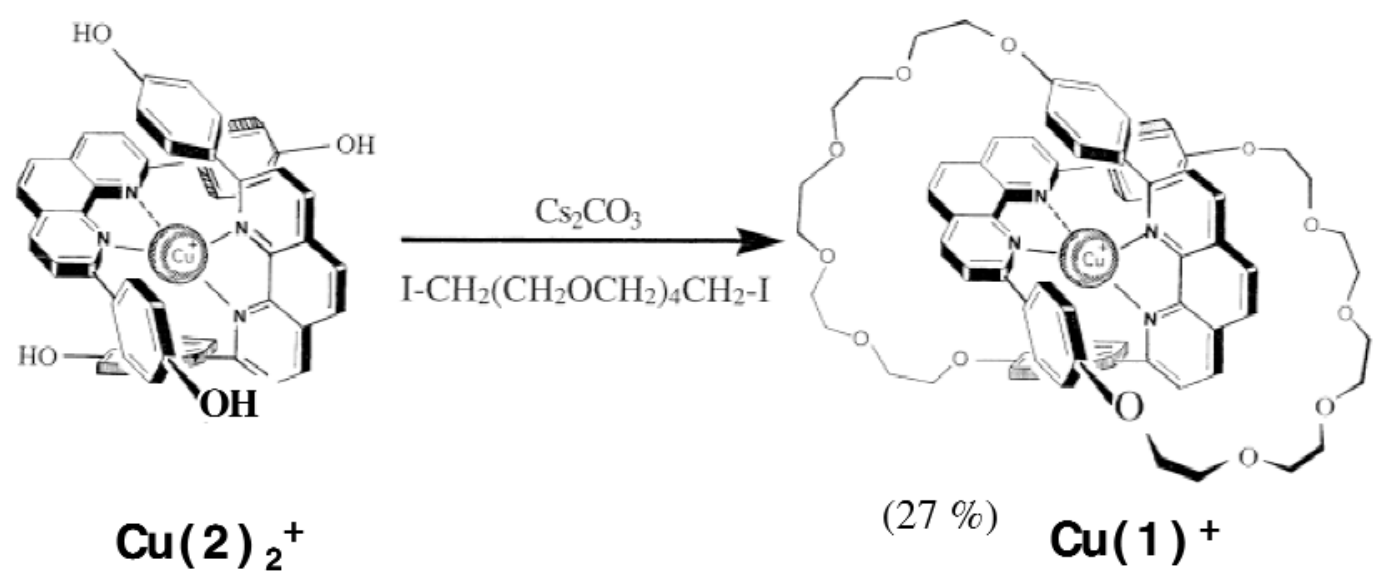

Fig. 4 Synthesis of the copper [2]catenane $\mathbf{C u}(\mathbf{1})^{+}$. 
verted to 2,9-bis(p-hydroxyphenyl)-1,10-phenanthroline 2 . It can thus be considered as the "universal precursor" of dpp-based copper catenanes [15].

The archetype of the family of copper [2]catenanes, $\mathbf{C u ( 1 ) ^ { + }}$ was thus synthesized using $\mathrm{Cu}(\mathrm{I})$ as a 3D template and 2,9-bis( $p$-hydroxyphenyl)-1,10-phenanthroline as ligand. $\mathbf{C u ( 2 )}{ }_{2}{ }^{+}$was here obtained quantitatively by mixing 1 equiv of $\mathrm{Cu}\left(\mathrm{CH}_{3} \mathrm{CN}\right)_{4} \mathrm{BF}_{4}$ and 2 equiv of 2 (Fig. 3). Reaction of $\mathbf{C u}(2)_{2}{ }^{+}$ with the diiodo derivative of pentaethylene glycol led to $\mathbf{C u}(\mathbf{1})^{+}$in a $27 \%$ yield (Fig. 4) $[5,15]$.

At this stage, the first gram-scale preparation of a [2]catenane was achieved and the way was open to the access to a fascinating new family of molecules. The compound could be crystallized, and an X-ray structure of it was obtained (Fig. 5). This was certainly the most convincing evidence for the interlocked topology of the molecule.

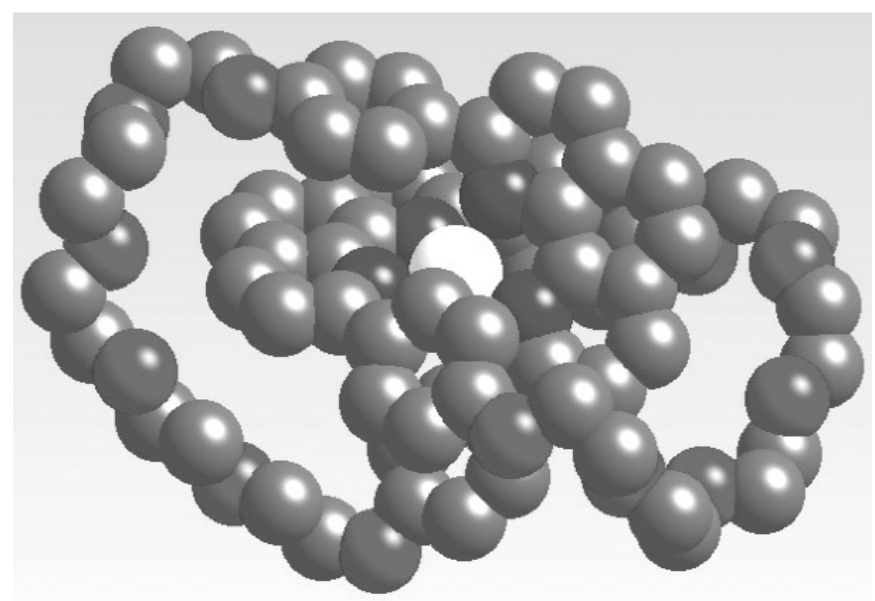

Fig. 5 Crystal structure of the copper [2]catenane $\mathbf{C u}(\mathbf{1})^{+}$. The $\mathrm{Cu}(\mathrm{I})$ atom is white.

The metal free [2]catenane $\mathbf{1}$ was obtained quantitatively by treatment of $\mathbf{C u}(\mathbf{1})^{+}$with tetramethylammonium cyanide in acetonitrile-water or by potassium cyanide in acetonitriledichloromethane-water (Fig. 6). The X-ray structure of the demetalation product, consisting of two interlocking rings, is shown in Fig. 7 [16]. In addition to being the most convincing proof of structure, the structures of $\mathbf{C u}(\mathbf{1})^{+}$and $\mathbf{1}$ are the two first X-ray structures of compounds containing interlocking rings.

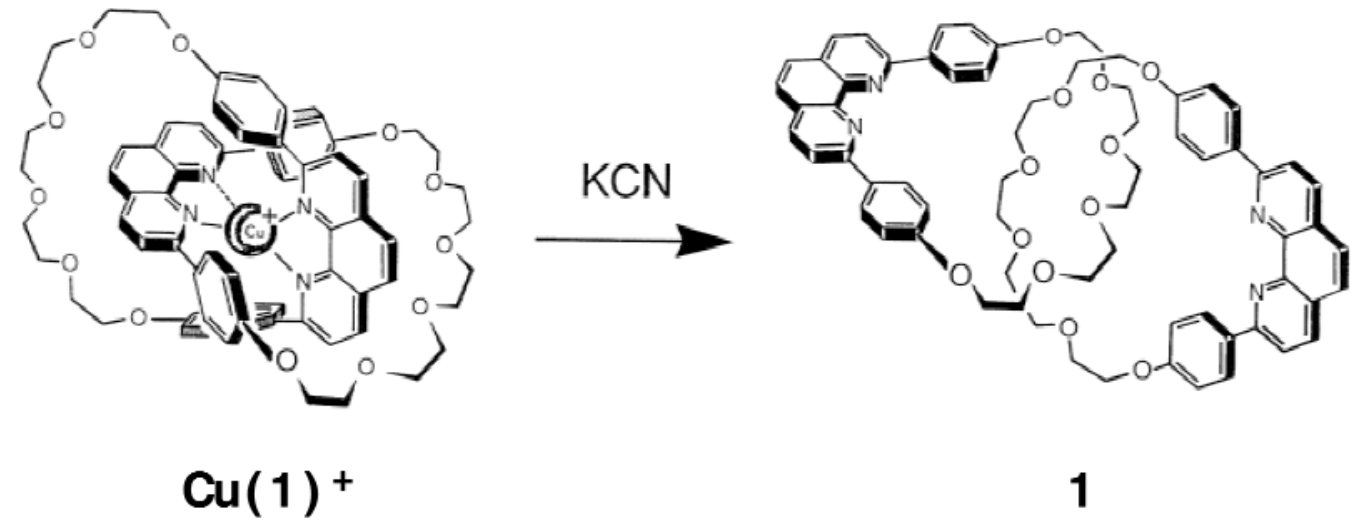

Fig. 6 Synthesis of the free [2]catenane 1 by demetalation reaction. 


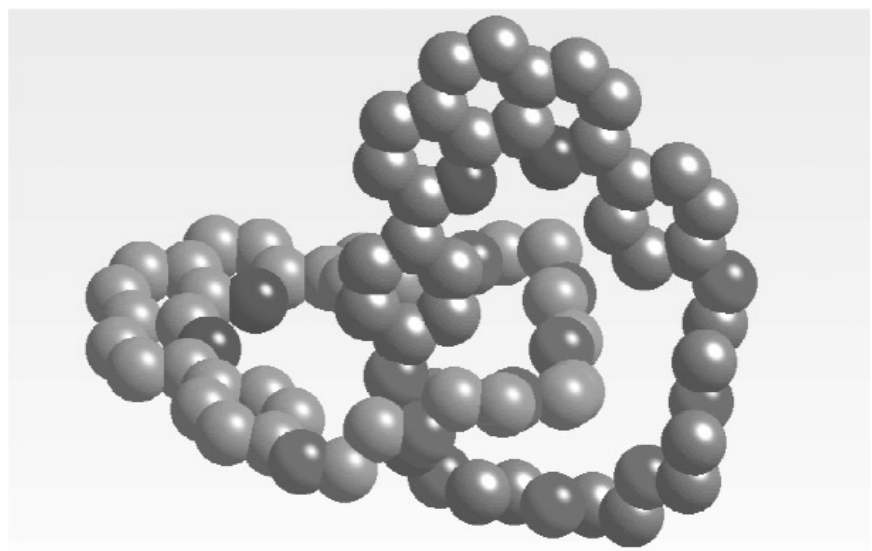

Fig. 7 Crystal structure of the free [2]catenane 1 .

The reaction conditions required by strategy A as well as strategy B for the nucleophilic displacement of the halide ions in fragment g-g represent a real synthetic difficulty. Indeed, the stability of the $\mathbf{C u}(\mathbf{2})_{2}{ }^{+}$in basic medium is rather limited, especially at high temperature. A new approach was developed more recently, which utilizes a combination of the same transition metal-based template strategy described above and of the efficient approach to macrocyclic systems displayed by ring-closing metathesis (RCM). This spectacular enhancement of the efficiency of the catenation reaction, which allowed the access to molecular systems of high topological complexity, is depicted in a schematic fashion in Fig. 8.

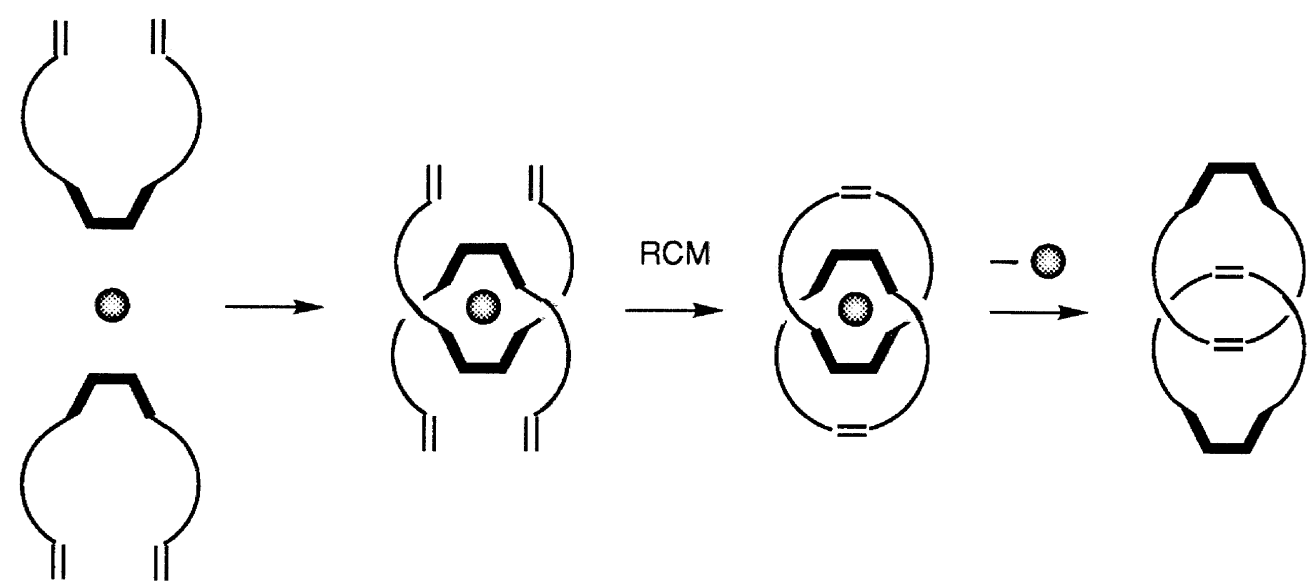

Fig. 8 Synthetic strategy leading to [2]catenane based on transition-metal template strategy and RCM reaction.

\section{MOLECULAR MACHINES CONSTRUCTED ON TRANSITION METAL-CONTAINING CATENANES AND ROTAXANES}

In biology, molecular machines and motors play an essential role [17]. Many examples are known of proteins that undergo important shape changes, such as folding/defolding, after a signal has been sent to the molecules [18].

Molecular motors consist of several components, among which some parts will be considered as motionless and others will move continuously while energy is consumed (ATP hydrolysis or pH-gradient consumption). Biological motors can be classified as rotary or linear motors, ATP synthase being 
certainly the most important and best understood rotary motor [19]. Artificial molecular machines and motors appear as one of the emerging fields of chemistry in the past decade [20]. Molecules or molecular assemblies, for which a certain part can be set into motion deliberately, have triggered great interest as "machines" in the course of the last decade [21]. Several such systems have been designed and elaborated recently, many of them being based on electroactive compounds whose shape will be modified at will by a redox process. Threaded or interlocking rings [22] are ideally suited to the construction of machines or motors since large-amplitude motions can be envisaged with such architectures without the risk of damaging the chemical structure of the system. If a ring is threaded onto a rod, it can either spin around the axle or undergo a translation movement. In a similar way, a ring can glide and spin within another ring in interlocking ring systems (catenanes).

Clearly, the functioning of skeletal muscles is the best understood linear motor [23]. The actin/myosin linear motor, which constitutes the most important part of muscles, has been extensively studied in the past three decades. There is obviously some analogy between the motion of actin filaments with respect to myosin-containing filaments (thick filament) and classic motors consisting of a piston moving in a cylinder (see Fig. 9).

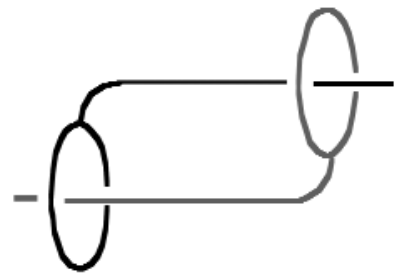

Contracted situation

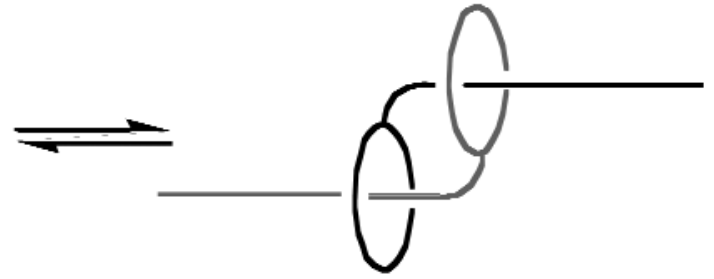

Extended situation

Fig. 9 The topology and shape of a linearly arranged pseudo-rotaxane dimer are adapted to a contraction/stretching motion.

One-dimensional molecular assemblies able to undergo stretching and contraction motions under the action of an external signal, similar to those observed in the real muscles, appeared as an exciting target. Several interesting artificial systems have been described, which aim at reproducing some essential properties of skeletal muscles. Polypyrrole-based devices are particularly promising, allowing one to bend a solid polymer film in one direction or another depending on the sign of an electric current applied to the film [24]. Another recent approach relies on single-walled nanotube sheets [25].

However, unimolecular linear arrays capable of undergoing contraction or stretching had so far not been made.

By analogy with real muscles, a molecular assembly in which two filaments can glide along one another was designed. This is the very process taking place in the sarcomere, in which the thick filament (containing myosin) moves along the thin filament (actin polymer) in one direction or the other so as to induce contraction or stretching. In the doubly threaded object of Fig. 9, the motion is easy to visualize. Both strings (mimicking the muscle filaments) move along one another, but stay together thanks to the rotaxane nature of the system.

The compound contains $\mathrm{Cu}(\mathrm{I})$ as the assembling and templating metal. The movement is induced by a chemical reaction, corresponding to metal exchange [26]. As shown in Fig. 10, the doubly threaded compound reported here can bind simultaneously two metal centers, either in a four- or five-coordinate geometry [26]. The four-coordinate situation results from the coordination of a $\mathrm{Cu}(\mathrm{I})$ ion with two phenanthroline units and corresponds to an extended geometry (upper part of Fig. 10), whereas the fivecoordinate situation results from the coordination of a divalent ion $\mathrm{M}$ with one phenanthroline and one terpyridine and leads to a contracted geometry (bottom of Fig. 10).

A macrocycle containing a 2,9-diaryl-1,10-phenanthroline (synthesized in several steps from commercially available compounds) [15] was covalently linked to a linear 2,9-dimethyl-3,8-bis-( $p$-hy- 


$$
\begin{aligned}
& \square=\begin{array}{l}
\text { phen } \\
\text { (bidentate) }
\end{array} \\
& \bigwedge=\text { terpy } \\
& \text { (terdentate) }
\end{aligned}
$$

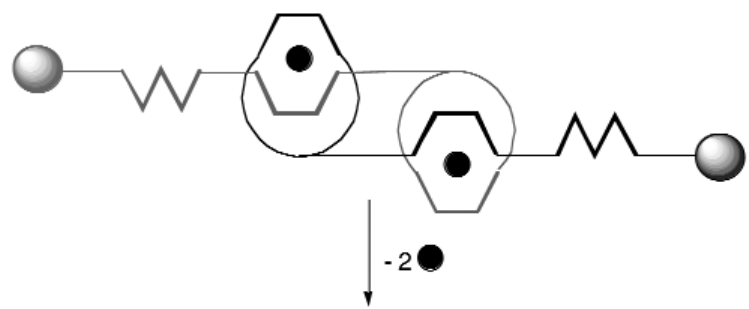

$=\mathrm{Cu}$ (I) 4-coordinate

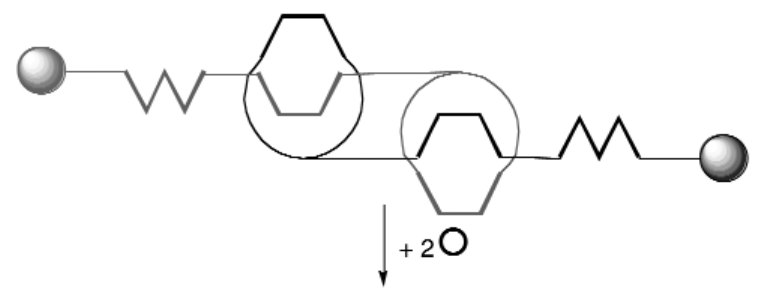

$\mathrm{O}=\mathbf{Z n}$ (II) 5 -coordinate

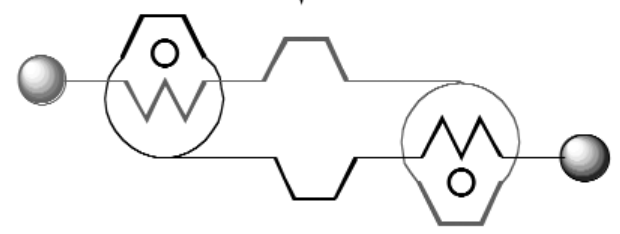

Fig. 10 Reversible chemically induced motions between extended rotaxane dimer and contracted assembly.

droxyphenyl)-1,10-phenanthroline and the bis-chelating target ligand $\mathbf{3}$ was obtained in $51 \%$ yield [26]. The reaction of 3 with a stoichiometric amount of $\left[\mathrm{Cu}\left(\mathrm{CH}_{3} \mathrm{CN}\right)_{4}\right] \mathrm{PF}_{6}$ in $\mathrm{CH}_{3} \mathrm{CN}_{2} \mathrm{CH}_{2} \mathrm{Cl}_{2}$ at room temperature led quantitatively to $4^{2+}$ as its $\mathrm{PF}_{6}{ }^{-}$salt (Fig. 11). The success of this latter reaction was obviously far from being certain, considering the number of $\mathrm{Cu}(\mathrm{I})$ complexes which could be formed by coordinating the two different coordination sites of the ligand to the metal in the various possibilities. We
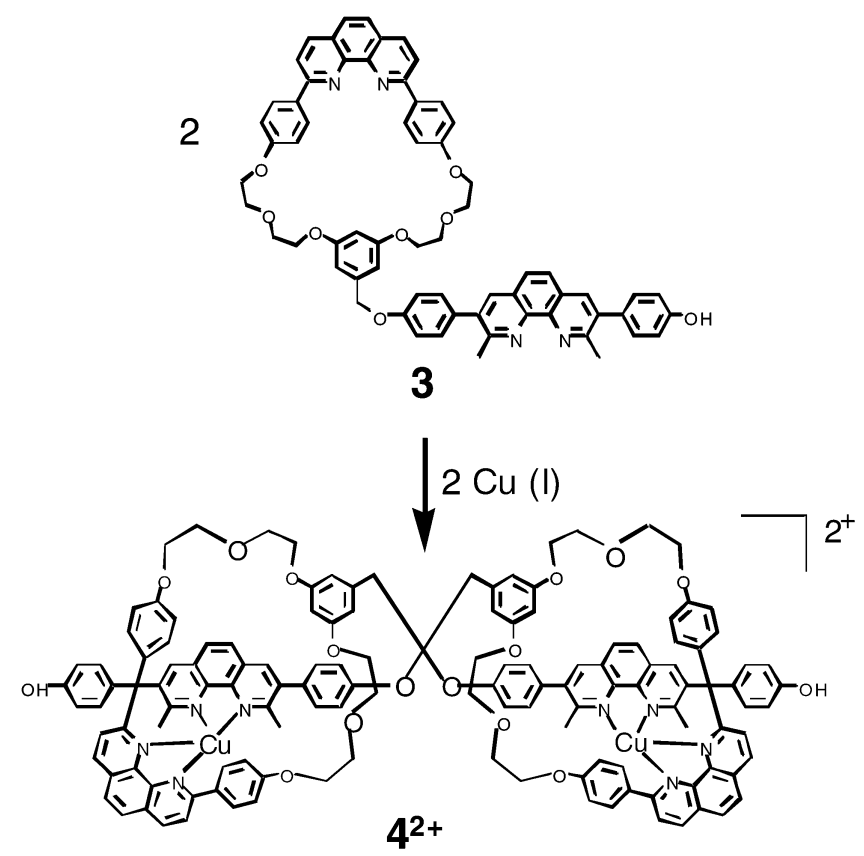

Fig. 11 The $\mathrm{Cu}(\mathrm{I})$-induced threading process leading to the dimer $\mathbf{4}^{\mathbf{2 +}}$.

(C) 2003 IUPAC, Pure and Applied Chemistry 75, 1383-1393 
were happy to note that the formation of the doubly threaded complex was quantitative, although very slow. In fact, the complexity of the complexation reaction is reflected by the time needed to reach equilibrium: Many coordination/decoordination reaction processes have to take place before the system finds its thermodynamic well (i.e., the doubly threaded species $\mathbf{4}^{2+}$ is obtained pure). Dimer $\mathbf{4}^{2+}$ was isolated as a deep red crystalline solid, and X-ray quality crystals were obtained from acetone/diethyl ether by diffusion. The molecular structure of the dinuclear dimer $\mathbf{4}^{2+}$, which possesses only a single $C_{2}$ axis, is given in Fig. 12.

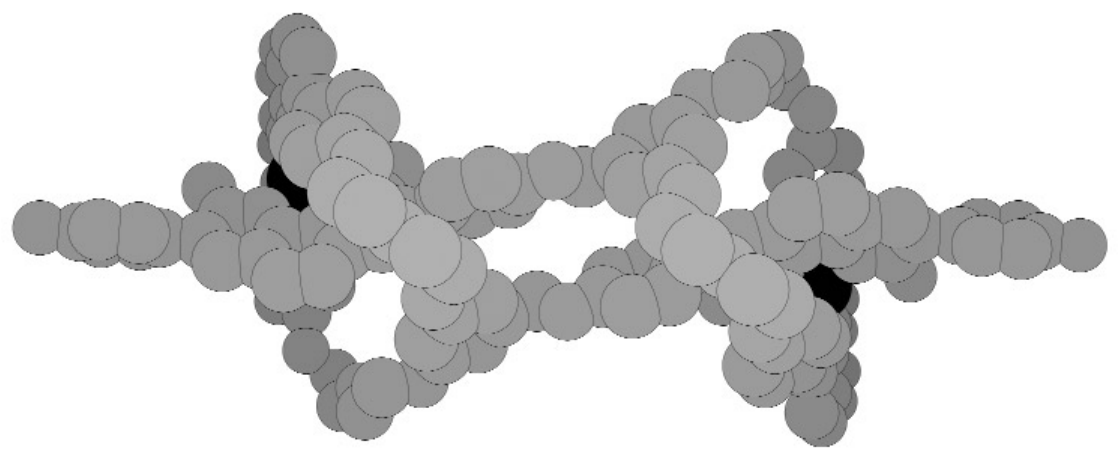

Fig. 12 Crystal structure of the dicopper(I) dimer $4^{2+}$.

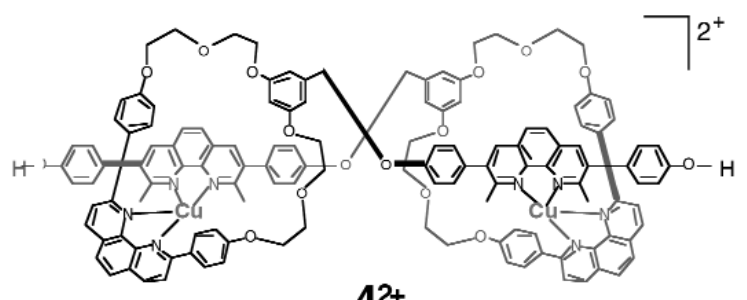

$4^{2+}$

$\mathrm{Cs}_{2} \mathrm{CO}_{3}, 40^{\circ} \mathrm{C}, \mathrm{DMF}$
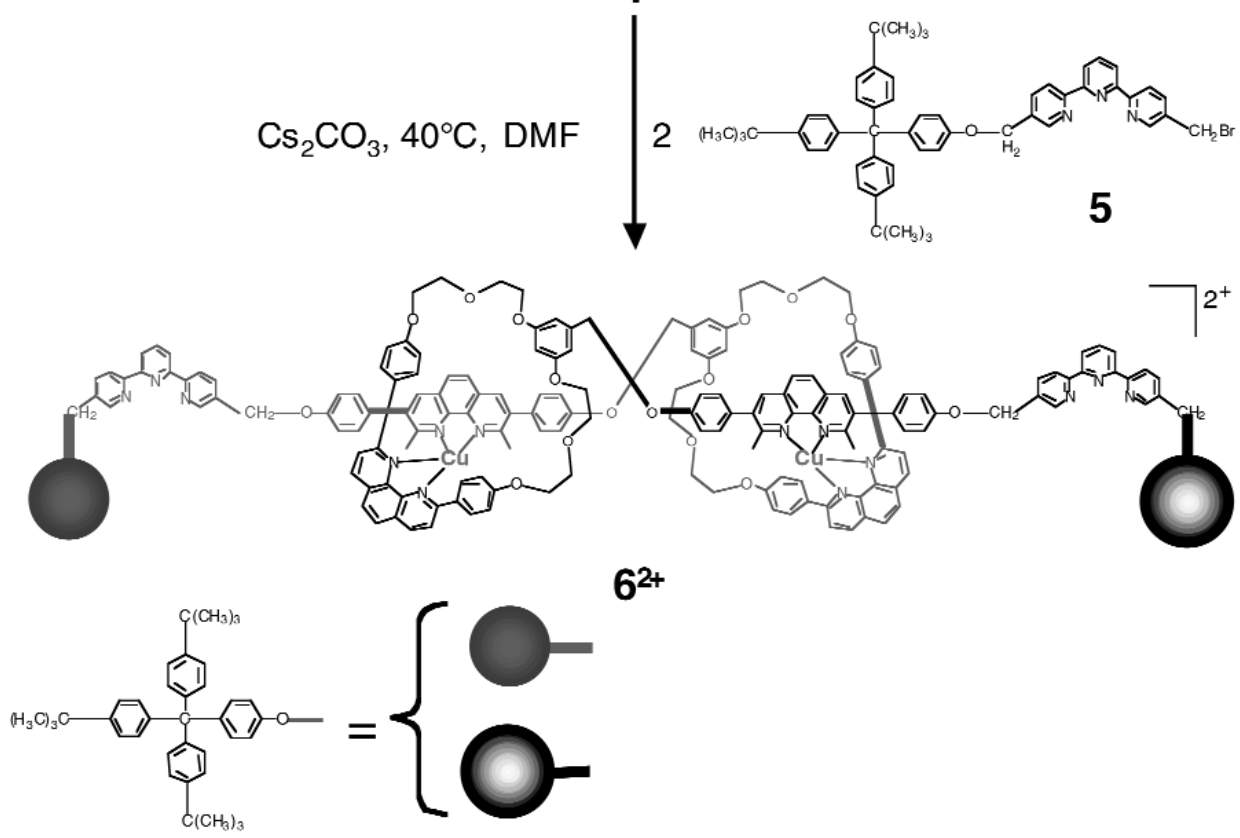

Fig. 13 Synthesis of the "muscle" $\mathbf{6}^{2+}$ in its extended situation. 
After separate synthesis of the functionalized $2,2^{\prime}: 6^{\prime}, 2^{\prime \prime}$-terpyridine 5 bearing a bulky stopper, the last step consisted in connecting the hermaphrodite dicopper(I) precursor $4^{2+}$ and 2 equiv of such terdentate coordinating units (Fig. 13). This last reaction was performed in DMF at $40{ }^{\circ} \mathrm{C}$ and permitted the synthesis of the "muscle" $\mathbf{6}^{\mathbf{2 +}}$ in an extended form as a dark red solid in $60 \%$ yield. This reaction not only allowed the introduction of terdentate sites into the molecular assembly, but also gave access to a real rotaxane structure in which any dethreading process was prohibited due to the presence of the two bulky stoppers.

Treatment of $\mathbf{6}^{\mathbf{2 +}}$ with a large excess of $\mathrm{KCN}$ at room temperature gives the free ligand in quantitative yield, which after remetalation with $\mathrm{Zn}\left(\mathrm{NO}_{3}\right)_{2}$ gives the colorless dizinc complex $\mathbf{7}^{\mathbf{4 +}}$ quantitatively in a contracted form (Fig. 14). The extended dicopper(I) dimer $6^{2+}$ may be regenerated by the reaction of $7^{4+}$ with an excess of $\left[\mathrm{Cu}\left(\mathrm{CH}_{3} \mathrm{CN}\right)_{4}\right] \mathrm{PF}_{6}$ at room temperature.

By exchanging the metal, the muscle-like compound is set in motion, the $\mathrm{Cu}(\mathrm{I})$ complex being extended and the $\mathrm{Zn}(\mathrm{II})$-containing species being contracted.

The present rotaxane dimer represents the first example of an unimolecular linear array able to stretch and contract at will under the action of a chemical stimulus. From Corey-Pauling-Kultun (CPK) model estimations, the length of the compound changes from 83 to $65 \AA$ between both situations, that is, roughly of the same relative amount as natural muscles $(\sim 27 \%)$.
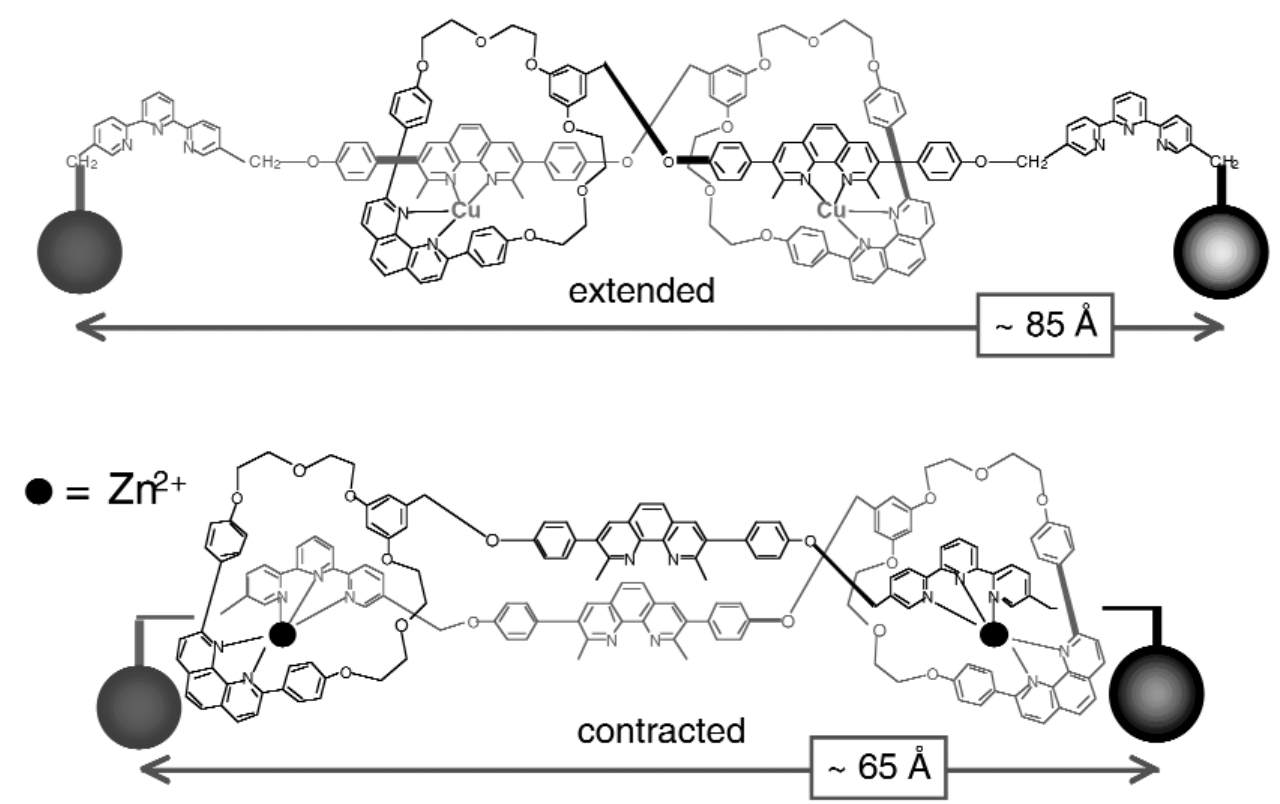

Fig. 14 The two states of the "muscle" induced by a metal exchange reaction.

\section{CONCLUSION}

The field of molecules in motion, for which movements and shape changes are triggered and controlled from the outside, has indisputably been one of the most rapidly developing areas of the past decade.

Several years ago, a 3D template strategy affording interlocking ring structures was developed. The strategy is based on a precursor that consists of two phenanthroline-type ligands entwined around a $\mathrm{Cu}(\mathrm{I})$ center. This construction principle has proven particularly successful for the preparation of gram-quantities of catenane and rotaxane, and allows the preparation of complex molecular assemblies.

In this article, we have discussed the most elaborated example of linear system, a rotaxane dimer whose behavior is reminiscent of a muscle. The stretching/contraction process is triggered by a chem- 
ical reaction, corresponding to metal exchange. The doubly threaded dimer can bind simultaneously two metal centers, either in a four- or five-coordinate geometry. The four-coordinate situation corresponds to an extended geometry, whereas the five-coordinate situation leads to a contracted geometry.

This process illustrates the ability of transition-metal centers to govern the geometry of relatively complex molecular assemblies and demonstrates the power of $\mathrm{Cu}(\mathrm{I})$ as a gathering and threading center.

\section{REFERENCES}

1. V. Balzani, A. Credi, F. M. Raymo, J. F. Stoddart. Angew. Chem., Int. Ed. 39, 3348-3391 (2000).

2. G. Schill. Catenanes, Rotaxanes and Knots, Academic Press, New York (1971).

3. E. Wasserman. J. Am. Chem. Soc. 82, 4433-4434 (1960).

4. I. T. Harrison and S. Harrison. J. Am. Chem. Soc. 89, 5723-5724 (1967).

5. C. Dietrich-Buchecker, J.-P. Sauvage, J.-P. Kintzinger. Tetrahedron. Let. 24, 5095-5098 (1983).

6. C. Dietrich-Buchecker, J.-P. Sauvage, J.-M. Kern. J. Am. Chem. Soc. 106, 3043-3045 (1984).

7. P. R. Ashton, T. T. Goodnow, A. E. Kaifer, M. V. Reddington, A. M. Z. Slawin, N. Spencer, J. F. Stoddart, C. Vicent, D. J. Williams. Angew. Chem. 101,1404-1408 (1989).

8. C. A. Hunter. J. Am. Chem. Soc. 114, 5303-5311 (1992).

9. F. Vogtle, S. Meier, R. Hoss. Angew. Chem., Int. Ed. 31, 1619-1622 (1992).

10. J.-C. Chambron, C. Dietrich-Buchecker, C. Hemmert, A. K. Khemiss, D. Mitchell, J.-P. Sauvage, J. Weiss. Pure Appl. Chem. 62, 1027-1034 (1990).

11. A. Livoreil, C. Dietrich-Buchecker, J.-P. Sauvage. J. Am. Chem. Soc. 116, 9399-9400 (1994).

12. M.-J. Blanco, M.-C. Jiménez, J.-C. Chambron, V. Heitz, M. Linke, J.-P. Sauvage. Chem. Soc. Rev. 28, 293-305 (1999).

13. F. Arnaud-Neu, E. Marques, M.-J. Schwing-Weill, C. Dietrich-Buchecker, J.-P. Sauvage, J. Weiss. New J. Chem. 12, 15-20 (1988).

14. C. Dietrich-Buchecker, P. A. Marnot, J.-P. Sauvage, J.-P. Kintzinger, P. Maltese. Nouveau J. Chim. 8, 573-582 (1984).

15. C. Dietrich-Buchecker and J.-P. Sauvage. Tetrahedron 46, 503-512 (1990).

16. M. Cesario, C. O. Dietrich-Buchecker, J. Guilhem, C. Pascard, J.-P. Sauvage. J. Chem. Soc., Chem. Commun. 244-247 (1985).

17. (a) K. Kitamura, M. Tokunaga, A. H. Iwane. Nature 397, 129-134 (1999); (b) J. Howard. Nature 389, 561-567 (1997); (c) T. Elston, H. Wang, G. Oster. Nature 391, 510-513 (1998).

18. T. Pascher, J. P. Chesick, J. R. Winkler, H. B. Gray. Science, 271, 1558-1560 (1996).

19. (a) H. Noji, R. Yasuda, M. Yoshida, K. Kinosita. Nature, 386, 299-302 (1997); (b) J. E. Walker. Angew. Chem., Int. Ed. 37, 2308-2319 (1998).

20. (a) V. Balzani, M. Gómez-López, J. F. Stoddart. Acc. Chem. Res. 31, 405-414 (1998); (b) J.-P. Sauvage. Acc. Chem. Res. 31, 611-619 (1998); (c) L. Fabbrizzi, M. Licchelli, P. Pallavicini. Acc. Chem. Res. 32, 846-853 (1999); (d) T. R. Kelly, H. De Silva, R. A. Silva. Nature 401, 150-152 (1999); (e) N. Koumura, W. J. Zijlstra, R. A. Van Delden, N. Harada, B. L. Feringa. Nature 401, 152-155 (1999).

21. (a) R. A. Bissell, E. Córdova, A. E. Kaifer, J. F. Stoddart. Nature 369, 133-137 (1994); (b) L. Zelikovich, J. Libman, A. Shanzer. Nature 374, 790-792 (1995).

22. (a) C. O. Dietrich-Buchecker and J.-P. Sauvage. Chem. Rev. 87, 795-810 (1987); (b) D. B. Amabilino and J. F. Stoddart. Chem. Rev. 95, 2725-2828 (1995); (c) R. Jäger and F. Vögtle. Angew. Chem., Int. Ed. 36, 930-944 (1997); (d) M. Fujita. Chem. Soc. Rev. 27, 417-426 (1998); (e) J.-P. Sauvage, C. Dietrich-Buchecker, G. Rapenne. Molecular Catenanes, Rotaxanes and Knots, C. Dietrich-Buchecker and J.-P. Sauvage (Eds.), Wiley-VCH, Weinheim (1999); (f) J.-C. Chambron. In Transition Metals in Supramolecular Chemistry, J.-P. Sauvage (Ed.), Chap. 6, Wiley, Chichester (1999). 
23. I. Rayment, H. M. Holden, M. Whittaker, C. B. Yohn, M. Lorenz, K. C. Holmes, R. Milligan. Science, 261, 58-65 (1993).

24. T. Otero and J. M. Sansinena. Adv. Mater. 10, 491-494 (1998).

25. R. H. Baughman, C. Cui, A. A. Zakhidov, Z. Iqbal, J. N. Barisci, G. M. Spinks, G. G. Wallace, A. Mazzoldi, D. De Rossi, A. G. Rinzler, O. Jaschinski, S. Roth, M. Kertesz. Science 284, 1340-1344 (1999).

26. (a) M. C. Jimenez, C. Dietrich-Buchecker, J.-P. Sauvage, A. De Cian. Angew. Chem., Int. Ed. 39, 1295-1298 (2000); (b) M. C. Jimenez, C. Dietrich-Buchecker, J.-P. Sauvage. Angew. Chem., Int. Ed. 39, 3284-3287 (2000); (c) M. C. Jimenez, C. Dietrich-Buchecker, J.-P. Sauvage. Chem. Eur. J. 8, 1456-1466 (2002). 